\title{
The effects of motor impulsiveness and optimism bias on risky driving behavior in Chinese urban areas
}

\author{
Li Jiang, Yongjuan Li, Xueyuan Liu
}

\begin{abstract}
The present study investigated the influence of motor impulsiveness and optimism bias on self-reported risky driving behavior. Two components of risky driving behavior, angry driving and traffic violation for convenience were identified. Structural Equation Modeling results supported motor impulsiveness directly predicting angry driving and traffic violation for convenience, with optimism bias partially mediating the relationship between motor impulsiveness and angry driving. Traffic violation for convenience was significantly related to safety performance. Practical implications and safety interventions were discussed.
\end{abstract}

\section{INTRODUCTION}

$\mathrm{S}$ ATISTICS from the Asia Development Bank illustrated hat mortality from traffic accidents in China for the period from 2000 to 2004 ranked highest in the world; one person died from a car accident every six minutes on average. The economic loss accounted for $1 \%$ to $3 \%$ GDP of China, which was higher than the budgets of the public health service and rural basic education ${ }^{[1]}$. In urban areas, traffic congestion is also becoming serious, especially during rush hours. In the city of Beijing, for example, the speed on the main road in 2006 was only half that of ten years ago, and sixty percent of 183 crossings are always seriously congested ${ }^{[2]}$.

It is commonly accepted that human factors were considered as the most central contributors of accidents ${ }^{[3-6]}$. Risky driving behavior or violations were seen as causes of road crashes and traffic congestion in urban cities, regardless of hardware and engineering facets ${ }^{[7]}$. The most investigated factors included personality variables (e.g. sensation seeking), cognition variables (e.g. risk perception), and attitudes.

The focus of present study was on the predictors of risky driving behavior in urban areas. We intended to integrate individual difference research and cognitive bias research to seek the overall prediction.

This work was supported in part by the National Natural Science Foundation of China under Grant 70401018 and in part by the Knowledge Innovation Project of the Chinese Academy of Sciences under Grant KSCX2-YW-R-130.

Li Jiang is with the Institute of Psychology, Chinese Academy of Sciences and Graduate University of Chinese Academy of Sciences, 4A Datun Road, Beijing 100101, China (e-mail: jiangli @ psych.ac.cn)

Yongjuan $\mathrm{Li}$ is with the Institute of Psychology, Chinese Academy of Sciences, 4A Datun Road, Beijing 100101, China (corresponding author, phone: 8610-6483-7339; fax: 8610-6487-2070; e-mail: liyj @ psych.ac.cn)

Xueyuan Liu is with the Institute of Psychology, Chinese Academy of Sciences and Graduate University of Chinese Academy of Sciences, 4A Datun Road, Beijing 100101, China (e-mail:liuxuey @ psych.ac.cn)
Risky driving behavior

Studies on risky driving behavior can be traced back to Reason and his colleagues' work. They developed a measure of risky driving behavior named Driving Behavior Questionnaire (DBQ). The DBQ classifies risky driving behavior into violation, lapses and slips ${ }^{[8-9]}$ although other following researchers have found a variety of dimensions, which were probably due to the different scale items and samples ${ }^{[10-12]}$. Violation was the only dimension that was found to predict accidents ${ }^{[13]}$. The violation behaviors found by western researchers included chase a driver who angered you, break speed limit, etc. While in China, a couple of distinctive unsafe driving behaviors had been explored, including changing lanes illegally; using a non-motor lane when there was congestion; and jumping a queue when there was congestion on the approach to a junction, etc.

The current study measured driving behavior using the violation behaviors from the combined items developed by Reason, Parker and their colleagues ${ }^{[8-9]}$, with the behaviors found in Chinese drivers only.

\section{Motor impulsiveness}

Impulsiveness deals with one's control over one's thoughts and behaviors ${ }^{[14]}$. It was found as a direct personality predictor of risk taking, such as driving anger ${ }^{[15]}$, aggressive driving ${ }^{[16]}$ and violation ${ }^{[17]}$. While researchers argued that the indirect effect of personality on driving behaviors is rarely explored ${ }^{[18]}$. In the present study, we sought to find both the direct and indirect influence of this personality characteristic.

We selected motor impulsiveness, which is one of the sub-dimensions of impulsiveness describing one's control over actions or behaviors to measure drivers' impulsiveness. Items from the brief Barratt impulsiveness scale-Version 11 (BIS-11) ${ }^{[19]}$ were employed in the present study. It was hypothesized that:

Hypothesis 1: Motor impulsiveness is positively related with risky driving behavior.

\section{Optimism bias}

Optimism bias, or unrealistic optimism refers to "the tendency for people to believe they are less likely to experience negative events than similar others" ${ }^{[20]}$. Research has supported Westerners' distorted perception of personal vulnerability in many life areas, for example, marriage or 
divorce $^{[21]}$, skin cancer ${ }^{[22]}$ or infected with HIV incidence ${ }^{[23-24]}$, etc. Research in health psychology has found unrealistically optimistic individuals possessed a distorted personal health risk ${ }^{[25]}$, learned less health knowledge ${ }^{[26]}$, with less health promoting behavior ${ }^{\text {[22, 26-27]. }}$

Driving research also indicated optimism bias of drivers was present for driving related questions, such as crash-risk optimism ${ }^{[28]}$, however, its relation to risky driving behavior was seldom deeply explored.

Articles referring to optimism bias are mostly based on western samples. Cross-cultural research has found that Westerners were more vulnerable to optimism bias than Easterners ${ }^{[29]}$, although Jiang and her colleagues found that Chinese drivers also show unrealistic optimism to some degree in their preliminary study ${ }^{[30]}$.

We expected that drivers' optimism bias would be positively related to risky driving behavior. As unrealistic optimism, a self-enhancement bias ${ }^{[29]}$ was associated with processing deficits and defensiveness ${ }^{[26]}$. Therefore, it would be expected that people with high motor impulsiveness would be less likely to process risk information, and people with high unrealistic optimism would increase this tendency. Namely, high motor impulsiveness people would be more vulnerable to this bias. Based on this, the following hypotheses were made:

Hypothesis 2: optimism bias is positively related with motor impulsiveness.

Hypothesis 3: optimism bias would mediate the relationship between motor impulsiveness and risky driving behavior.

\section{Aims}

The present study explored predictors of risky driving behavior of drivers in urban areas. Participants of this study were car drivers of private cars, which account for 72.6 percent of the total drivers in China ${ }^{[31]}$.

As the integration of personality and cognition variables could effectively improve the prediction of risky driving behavior $^{[18]}$, we explored the overall effect of motor impulsiveness and optimism bias on driving behavior. Motor impulsiveness was expected to show a direct effect on risky driving behavior with optimism bias would mediate this relationship.

\section{METHOD}

Participants

Participants were 108 adult drivers aged from 20 years old to 59 years old. Participants have been driving from 1 year to 33 years with an average driving age of five years. Most of the participants were non-professional drivers $(96.2 \%)$ with higher education levels (76.2\% with Bachelor degree and $15.2 \%$ with Master degree). $61.1 \%$ were female, and $76.2 \%$ drove only in urban areas.
Instruments

The risky driving behavior questionnaire consisted of two parts. 9 items were from Driving Behavior Questionnaire (DBQ) ${ }^{[32]}$, and 3 additional items were adapted from Xie and Parker's research ${ }^{[33]}$ reflecting violation behaviors in China.

The present study used a 5-item motor impulsiveness scale, from a brief Barratt impulsiveness scale version $15^{[19]}$.

A within-groups method was used to measure optimism bias ${ }^{[29]}$. Participants were asked "compared to other drivers-the same driving age as you-- what do you think are the chances that traffic accident will happen to you?" participants responded on a 5-point rating scale from -2 (much below average) to 2 (much above average).

In safety research, accidents are relatively rare and frequently do not have a normal distribution. Researchers argue accident data is an unreliable and unsuitable criterion from the psychometric view ${ }^{[18]}$. Aggregation of different indicators across situations was suggested ${ }^{[34]}$. Thus, we added a new indicator to measure the outcome besides the accident experience, which was the penalty and punishment scores during the illegal driving rather than parking illegally received from policemen. We labeled these indicators personal safety performance.

\section{Demographics}

Participants also indicated their age, gender, driving age, education background, and history of traffic accidents, car type, insurance information and so on.

\section{Statistical analysis}

Descriptive statistical analysis was performed using SPSS; Confirmatory factor analysis (CFA) and structural equation model (SEM) was performed using Amos 7.0. Structural equation model was used to estimate the relationship between motor impulsiveness, optimism bias and risky driving behavior, as well as punishment record.

Fit of the model was assessed by several indices. Four of those indices were used in the present study. They are the comparative fit index (CFI), incremental fit index (IFI), Tucker Lewis Index (TLI), and the root mean square error of approximation (RMSEA). CFI, IFI, and TLI values greater than .90 indicate a good fit of the model to data ${ }^{[35]}$. An RMSEA of 0.08 or lower indicates a good fit ${ }^{[36]}$.

\section{RESULTS}

Risky driving behavior

First, to test the reliability and construct validity of the driving behavior questionnaire, another sample of 55 drivers were asked to report their unsafe driving behavior on a 7 -point scale $(1=$ never to $7=$ nearly all the time). These data were submitted to exploratory factor analysis (EFA) with principal component extraction and varimax rotation. The eigenvalues of three factors were larger than 1 , however, the scree plot suggested a two-factor solution. Three 
cross-loading items were deleted. Responses to the remaining 9 items were submitted to another exploratory factor analysis. Table 1 shows the results with item loadings on the two factors, angry driving and violation for convenience. The items with the lowest loadings from each of the two factors were not included in the later study.

The factor structure of the driving behavior questionnaire was examined using data from 108 drivers by confirmatory factor analysis. A two-factor model fit the data well with all the parameters meeting the requirements $(\mathrm{CFI}=0.92$, $\mathrm{IFI}=0.92, \mathrm{RMSEA}=0.09$, Chi-square $=26.6, \mathrm{df}=13, \mathrm{p}=0.02$ ).

TABLE 1

FACTOR STRUCTURE AND LOADING OF NINE DRIVING BEHAVIOR ITEMS

\begin{tabular}{lcc}
\hline \multicolumn{1}{c}{ Items } & Factor 1 & Factor 2 \\
\hline sound your horn to indicate your annoyance & 0.84 & \\
become angered by a certain type of driver & 0.83 & \\
chase a driver who angered you & 0.57 & 0.41 \\
not stop at red lights & 0.43 & \\
jumping a queue when there was congestion & & 0.78 \\
changing lanes illegally & & 0.71 \\
using a non-motor lane when there was congestion & & 0.69 \\
break speed limit & 0.42 & 0.44 \\
drink and drive & & 0.39 \\
\hline Variance (\%) & 24.45 & 23.97 \\
\hline
\end{tabular}

Extraction Method: Principal Component Analysis. Rotation Method: Varimax with Kaiser Normalization. Rotation converged in 3 iterations.

Motor impulsiveness

Confirmatory factor analysis was used to test the construct structure. Results indicated high construct validity (CFI $=0.99, \mathrm{IFI}=0.99, \mathrm{RMSEA}=0.03$, Chi-square $=5.65, \mathrm{df}=5$, $\mathrm{p}=0.34$ ).

\section{Optimism bias}

Consistent with traditional test of optimism bias ${ }^{[29]}$, the 5-point response scale was recoded from -2 to 2 , respectively. Values significantly less than zero indicated an optimism bias. Based on a one-sample T-test, the results found drivers in the present research showed optimism bias towards traffic accidents $(\mathrm{t}=-15.726, \mathrm{df}=107, \mathrm{p}<0.001)$.

\section{Structural Equation Modeling}

Relationships between motor impulsiveness, optimism bias and risky driving behavior were examined using AMOS 7.0. The full model and the revised model were compared. The fitness indices of the full model indicated it was not good enough fit to the data, CFI $=0.92, \mathrm{IFI}=0.93$, TLI $=0.89$, RMSEA $=0.05$, Chi-square $=109.3, \mathrm{df}=84, \mathrm{p}=0.03$. Optimism bias didn't significantly predict violation for convenience and angry driving behavior did not significantly predict driving record. Thus, these two paths were deleted. However, it was thought that angry driving behavior may indirectly predict the outcome through violation for convenience. We added this path in the revised model. Comparatively, the revised model was a good fit to the data, $\mathrm{CFI}=0.94$, IFI $=0.94$, TLI $=0.91$, RMSEA $=0.04$, Chi-square $=104.49, \mathrm{df}=85, \mathrm{p}=0.07$. The results of the revised model are presented in Fig.1 with standardized coefficients. Indicators of the latent variables were not illustrated in the figure.

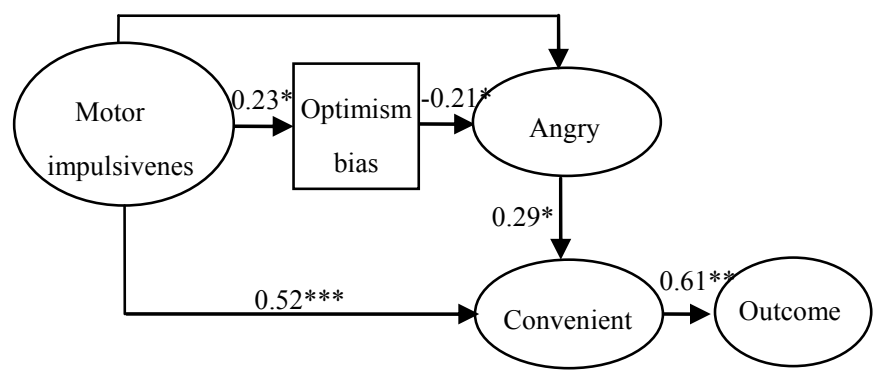

Fig.1. the revised model: predictors of risky driving behavior and outcome. $* * * \mathrm{p}<0.001, * * \mathrm{p}<0.01, * \mathrm{p}<0.05$

\section{DISCUSSION}

The main aim of the present study was to explore the overall prediction of motor impulsiveness and optimism bias on risky driving behavior. Results indicated that motor impulsiveness directly predicts angry driving and violation for convenience. Additionally, optimism bias partially mediated the influence of motor impulsiveness on anger driving.

Consistent with previous research, people with high motor impulsiveness demonstrated more angry driving behavior ${ }^{[15]}$. High impulsiveness people showed a tendency toward acting without thought and making quick decisions, which has been found to be related to lower overall capacity working memory with greater restricted access ${ }^{[37]}$. So it was much easier for them to use the vehicle to express anger towards other road users; they didn't consider the driving circumstances on the road, process risk information and usually commit small violations, such as jumping a queue when there is congestion.

Different from Hypothesis 3, optimism bias only mediated the relationship between motor impulsiveness and angry driving behavior. Optimism bias was more effective in predicting emotional (angry) driving behavior. For violation for convenience, apart from the direct relation from motor impulsiveness, angry driving behavior also was another significant predictor of violation for convenience, which supports the notion that becoming frustrated and angry in traffic situations can easily trigger rule violation responses ${ }^{[18]}$. 
Consistent with our expectation, violation for convenience can directly predict personal safety performance, which indicated those small violations may be a precursor to road incidents and accidents. In urban areas, those small violations may become the intervention focus of traffic safety campaign from management perspective.

A practical implication of the results is that the effect of personality on safety should be taken into consideration. Researchers have suggested that personality assessment be used as a screening procedure when drivers take initial training ${ }^{[38]}$. Educators should pay special attention to drivers with high motor impulsiveness and provide additional safety intervention programs for them, such as self-awareness exercises which may help drivers reflect on their personality and its influence on their driving behavior, similar to the self-produced, individual decisions programs used behavioral change for professional drivers ${ }^{[18]}$.

Research has suggested ways to deal with anger responses in traffic, for example, focusing on situations that can trigger reactions such as self-assertion when driving with others, and impatience and frustration in traffic ${ }^{[15]}$. The method of behavior psychological therapy based on conditional and unconditional stimuli and response theory may be integrated in the program in future.

In China, the traditional traffic safety campaign strategy has been focused on severe road accidents through safety warning signs along the road. In urban cities, based on the relation between violation for convenience and personal safety performance found in this study, interventions focusing on violation for convenience of drivers could be an effective way to improve safety performance. In a word, integrated strategies can help to reduce the negative factors that can effect on safety from different angles.

\section{ACKNOWLEDGMENT}

The authors would like to thank Lixia Jin for her kind help in the data collection process, Professor Dr. Lois E Tetrick for her suggestions and polishing on the paper, as well as all the respondents who answered our questionnaire.

\section{REFERENCE}

[1] W. L. Li, "The loss of traffic accident is higher than the public health budget," sina.com, Dec. 15, 2005. [online]. Available:

finance.sina.com.cn/g/20051215/02342199402.shtml.[A ccessed: May 22, 2008] .

[2] Y. L. Ruan, "the speed on main road reduced 50\% compared with which of ten years' ago," xinhuanet.com, Dec. 2, 2006. [Online]. Available:

news.xinhuanet.com/local/2006-12/02/content_542360 7.htm.[Accessed: May 22, 2008] .

[3] J. Reason, Human Error, Cambridge University Press, 1990.

[4] E. D. Fleishman, L. C. Buffardi and R. A. Morach, "Development of a Model to predict Human Error Rates
From the Ability Requirement of Job Tasks," NRC-04-91-361, 1994.

[5] R. L. Helmreich, "Managing human error in aviation," Scientific American, vol.276, pp. 62-67, 1997.

[6] H. D. O, M. Wiggins, R. Batt and D. Morrison, "Cognitive failure analysis for aircraft accident investigation," Ergonomics, vol.37, pp. 1855-1869, 1994.

[7] "Ministry of Public Security notifies the national road traffic safety situation in 2005," Xinhuanet.com, Jan. 12, 2006.[Online]. Available:

news.xinhuanet.com/legal/2006-01/12/content_404252 6.htm.[Accessed: May 22, 2008] .

[8] J. Reason, A. Manstead, S. Stradling, J. Baxter and K. Campbell, "Errors and violations on the roads: a real distinction?," Ergonomics, vol.33, pp. 1315-1332, 1990.

[9] D. Parker, J. T. Reason, A. S. Manstead and S. G. Stradling, "Driving errors, driving violations and accident involvement," Ergonomics, vol.38, pp. 1036-1048, 1995.

[10] L. Aberg and P. A. Rimmo, "Dimensions of aberrant driver behaviour," Ergonomics, vol.41, pp. 39-56, 1998.

[11] T. Lajunen, D. Parker and H. Summala, "The Manchester Driver Behaviour Questionnaire: a cross-cultural study," Accident Analysis and Prevention, vol.36, pp. 231-238, 2004.

[12] G. M. Eugenia, M. J. Sullman, M. Cunill, M. Planes, M. Aymerich and S. Font-Mayolas, et al., "Spanish drivers and their aberrant driving behaviours," Transportation Research Part F: Psychology and Behaviour, vol.9, pp. 129-137, 2006.

[13] R. Lawton, D. Parker, A. S. Manstead and S. G. Stradling, "The Role of Affect in Predicting Social Behaviors: The Case of Road Traffic Violations," Journal of Applied Social Psychology, vol.27, pp. 1258-1276, 1997.

[14] E. S. Barratt, "Anxiety and Impulsiveness: Toward a Neuropsychological Model,", 1970.

[15] J. L. Deffenbacher, R. S. Lynch, L. B. Filetti, E. R. Dahlen and E. R. Oetting, "Anger, aggression, risky behavior, and crash-related outcomes in three groups of drivers," Behaviour Research and Therapy, vol.41, pp. 333-349, 2003.

[16] E. R. Dahlen, R. C. Martin, K. Ragan and M. M. Kuhlman, "Driving anger, sensation seeking, impulsiveness, and boredom proneness in the prediction of unsafe driving," Accident Analysis and Prevention, vol.37, pp. 341-348, 2005.

[17] C. Owsley, G. McGwin and S. F. McNeal, "Impact of impulsiveness, venturesomeness, and empathy on driving by older adults," Journal of Safety Research, vol.34, pp. 353-359, 2003.

[18] P. Ulleberg and T. Rundmo, "Personality, attitudes and risk perception as predictors of risky driving behaviour among young drivers," Safety Science, vol.41, pp. 427-443, 2003. 
[19] M. Spinella, "Normative data and a short form of the barratt impulsiveness scale," International Journal of Neuroscience, vol.117, pp. 359-368, 2007.

[20] N. D. Weinstein, "Unrealistic optimism about future life events," Journal of Personality and Social Psychology, vol.39, pp. 806-820, 1980.

[21] Y. C. Lin and P. Raghubir, "Gender Differences in Unrealistic Optimism About Marriage and Divorce: Are Men More Optimistic and Women More Realistic?," Personality and Social Psychology Bulletin, vol.31, pp. 198, 2005.

[22] R. Branstrom, S. Kristjansson and H. Ullen, "Risk perception, optimistic bias, and readiness to change sun related behaviour," The European Journal of Public Health, vol.16, pp. 492, 2006.

[23] R. S. Gold and H. M. Aucote, "I'm less at risk than most guys? gay men's unrealistic optimism about becoming infected with HIV," International Journal of STD \& AIDS, vol.14, pp. 18-23, 2003.

[24] R. S. Gold, "Explaining gay mens unrealistic optimism about becoming infected with HIV," International Journal of STD \& AIDS, vol.15, pp. 99-102, 2004.

[25] K. J. Prentice, J. M. Gold and W. T. Carpenter, "Optimistic Bias in the Perception of Personal Risk: Patterns in Schizophrenia," American Journal of Psychiatry, vol.162, pp. 507-512, 2005.

[26] N. M. Radcliffe and W. M. Klein, "Dispositional, Unrealistic, and Comparative Optimism: Differential Relations with the Knowledge and Processing of Risk Information and Beliefs about Personal Risk," Personality and Social Psychology Bulletin, vol.28, pp. 836-846, 2002.

[27] K. Davidson and K. Prkachin, "Optimism and Unrealistic Optimism have an Interacting Impact on Health-Promoting Behavior and Knowledge Changes," Personality and Social Psychology Bulletin, vol.23, pp. 617, 1997.

[28] J. R. Dalziel and R. F. Job, "Motor vehicle accidents, fatigue and optimism bias in taxi drivers.," Accident Analysis and Prevention, vol.29, pp. 489-494, 1997.

[29] S. J. Heine and D. R. Lehman, "Cultural variation in unrealistic optimism: Does the west feel more invulnerable than the east," Journal of Personality and Social Psychology, vol.68, pp. 595-607, 1995.

[30] L. Jiang, Y. J. Li and X. Y. Liu, "Unsafe driving behavior: a revised theoretical model based on theory of planned behavior," in Proc. 2007 Proceedings of the 11 th National Congress of Psychology.

[31] F. P. Xu, "Three million vehicle is the prosperous symbol," xinhuanet.com, May 25,2007.[Online]. available: news.xinhuanet.com/legal/2007-05/25/content_615109 5.htm.[Accessed: May 22,2008] .

[32] R. Lawton, D. Parker, A. S. Manstead and S. G. Stradling, "The role of affect in predicting social behaviours: The case of road traffic violations," Journal of Applied Social Psychology, vol.27, pp. 1258-1276, 1997.
[33] C. Xie and D. Parker, "A social psychological approach to driving violations in two Chinese cities," Transportation Research Part F: Psychology and Behaviour, vol.5, pp. 293-308, 2002.

[34] S. Epstein, "The stability of behavior: on predicting most of the people much of the time," Journal of personality and social psychology, vol.37, pp. 1097-1126, 1979.

[35] L. Hu and P. M. Bentler, "Structural equation modeling: concepts, issues and applications,"in Evaluating model fit, R. H. Hoyle, London: Sage Publications, 1995, pp. 76-99.

[36] M. W. Browne and R. Cudeck, in Alternative ways of assessing model fit, K. A. Bollen and J. S. Long, Newbury Park: Sage Publications, 1993, pp. 136-162.

[37] P. Whitney, T. Jameson and J. M. Hinson, "Impulsiveness and executive control of working memory," Personality and Individual Differences, vol.37, pp. 417-428, 2004.

[38] M. A. Machin and K. S. Sankey,"Relationships between young drivers? personality characteristics, risk perceptions, and driving behavior," Accident Analysis and Prevention, vol.40, pp. 541-547, 2008. 